\title{
A Gain-of-Function Mutation in Nav 1.6 in a Case of Trigeminal Neuralgia
}

\author{
Brian S Tanaka, ${ }^{1,2,3}$ Peng Zhao, ${ }^{1,2,3}$ Fadia B Dib-Hajj, ${ }^{1,2,3}$ Valerie Morisset, ${ }^{4}$ Simon Tate, ${ }^{4}$ Stephen G Waxman, ${ }^{1,2,3}$ \\ and Sulayman D Dib-Hajj ${ }^{1,2,3}$
}

${ }^{1}$ Department of Neurology; ${ }^{2}$ Center for Neuroscience and Regeneration Research, Yale University School of Medicine, New Haven, Connecticut, United States of America; ${ }^{3}$ Rehabilitation Research Center, Veterans Affairs Connecticut Healthcare System, West Haven; and ${ }^{4}$ Convergence Pharmaceuticals Ltd, Cambridge, United Kingdom

\begin{abstract}
Idiopathic trigeminal neuralgia (TN) is a debilitating pain disorder characterized by episodic unilateral facial pain along the territory of branches of the trigeminal nerve. Human pain disorders, but not TN, have been linked to gain-of-function mutations in peripheral voltage-gated sodium channels $\left(\mathrm{Na}_{v} 1.7, \mathrm{Na}_{v} 1.8\right.$ and $\left.\mathrm{Na}_{v} 1.9\right)$. Gain-of-function mutations in $\mathrm{Na}_{v} 1.6$, which is expressed in myelinated and unmyelinated central nervous system (CNS) and peripheral nervous system neurons and supports neuronal high-frequency firing, have been linked to epilepsy but not to pain. Here, we describe an individual who presented with evoked and spontaneous paroxysmal unilateral facial pain and carried a diagnosis of TN. Magnetic resonance imaging showed unilateral neurovascular compression, consistent with pain in areas innervated by the second branch of the trigeminal nerve. Genetic analysis as part of a phase 2 clinical study in patients with TN conducted by Convergence Pharmaceuticals Ltd revealed a previously undescribed de novo missense mutation in $\mathrm{Na}_{v}$ 1.6 (c.A406G; p.Met136Val). Whole-cell voltage-clamp recordings show that the Met136Val mutation significantly increases peak current density (1.5-fold) and resurgent current (1.6-fold) without altering gating properties. Current-clamp studies in trigeminal ganglia (TRG) neurons showed that Met $136 \mathrm{Val}$ increased the fraction of high-firing neurons, lowered the current threshold and increased the frequency of evoked action potentials in response to graded stimuli. Our results demonstrate a novel $\mathrm{Na}_{\mathrm{V}} 1.6$ mutation in $\mathrm{TN}$, and show that this mutation potentiates transient and resurgent sodium currents and leads to increased excitability in TRG neurons. We suggest that this gain-of-function $\mathrm{Na}_{\mathrm{V}} 1.6$ mutation may exacerbate the pathophysiology of vascular compression and contribute to TN.
\end{abstract}

Online address: http://www.molmed.org

doi: $10.2119 /$ molmed.2016.00131

\section{INTRODUCTION}

Trigeminal neuralgia $(\mathrm{TN})$ is characterized by recurring episodes of unilateral and lancinating facial pain along one or more branches of the trigeminal nerve (1). Neurovascular compression (NVC) of the trigeminal nerve is prevalent in TN with no other known comorbidities, and has been classically regarded as causing TN (1). Ultrastructural studies on biopsied trigeminal roots showed axonal loss, demyelination and dysmyelination consistent with NVC of the trigeminal nerve (2). However, recent studies have suggested that only severe neurovascular contact, causing displacement or atrophy of the nerve, is associated with pain in classical TN $(3,4)$, and some studies have questioned whether NVC is necessary and sufficient for TN, since pain can occur and recur in the absence of nerve compression $(5,6)$. A recent study reported

Address correspondence to Sulayman D Dib-Hajj, PhD, Neuroscience and Regeneration Research Center, VA Connecticut Healthcare System, 950 Campbell Avenue, Bldg. 34, West Haven, CT 06516 USA. Phone: 203-937-3802; Fax: 203-937-3801; E-mail: sulayman. dib-hajj@yale.edu.

Submitted May 13, 2016; Accepted for publication July 18, 2016; Published Online (www.molmed.org) August 3, 2016.

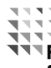

Feinstein Institute
for Medical Research Northwell Health" that TN without NVC is more prevalent in younger individuals (6). These findings suggest contributions of genetic and epigenetic factors to the pathophysiology of classical TN, especially in patients without severe NVC. Rare cases of familial idiopathic trigeminal pain with an autosomal dominant inheritance pattern (7-10) support a genetic component for TN.

The molecular basis for TN has thus far remained elusive. Its pathophysiology has been modeled by the "ignition theory" $(11,12)$, which posits that injured trigeminal neurons fire spontaneously and have a lower threshold for evoked afterdischarges leading to paroxysmal pain. Intraoperative microneurographic recordings in trigeminal nerve fibers after stimulation of the known trigger zone in a TN patient demonstrated afterdischarges that were absent when unaffected facial areas were stimulated (13), 
and consistent with the predictions of ignition theory, the period of intense afterdischarge was followed by a prolonged period refractory to additional stimulation. Voltage-gated sodium channel blockers carbamazepine and oxcarbazepine are the first-line pharmacotherapy for classical TN (1); thus, it is reasonable to suggest an involvement of voltage-gated sodium channels in its pathophysiology.

Rare and common painful disorders, but not TN, have been genetically and functionally linked to gain-of-function mutations in peripheral sodium channels $\mathrm{Na}_{\mathrm{V}} 1.7, \mathrm{Na}_{\mathrm{V}} 1.8$ and $\mathrm{Na}_{\mathrm{V}} 1.9$ (14-16). Although gain-of-function mutations of $\mathrm{Na}_{\mathrm{V}} 1.6$ have been shown to cause infantile epileptic encephalopathy (17-19), there has been no genetic evidence thus far for a role for this channel in human pain disorders. We report here a novel $\mathrm{Na}_{\mathrm{V}} 1.6$ mutation in an individual with TN. Functional testing shows that the substitution confers gain-of-function attributes on the channel and increases the excitability of trigeminal ganglion neurons that express the mutant channel. This data support a role of $\mathrm{Na}_{\mathrm{V}} 1.6$ in the pathophysiology of $\mathrm{TN}$, adding to the spectrum of excitability disorders linked to this channel.

\section{MATERIAL AND METHODS}

\section{Molecular Genetics}

The study was approved by an institutional review board. Genomic analysis was performed as part of a phase 2 clinical study in patients with trigeminal neuralgia conducted by Convergence Pharmaceuticals Ltd (NCT01540630; Tate et al., 2014). Next-generation sequencing utilizing a customized Agilent Haloplex Enrichment Panel and the Illumina MiSeq instrument was done to sequence the exonic regions of the targeted genes encoding voltage-gated sodium channels $\left(\mathrm{Na}_{\mathrm{V}} 1.1,1.2,1.3,1.6\right.$ and 1.7) and calcium channels $\left(\mathrm{Ca}_{\mathrm{V}} 2.1\right.$ and 2.2). Genomic DNA was isolated from whole-blood samples using a Qiagen DNA column-based purification kit. Quality and quantification checks were performed prior to PCR to ensure high-quality DNA. Bioinformatics analysis of the sequencing data and detection of mutations in the target channels were performed using GATK (Broad Institute of Massachusetts Institute of Technology, https://www.broadinstitute. org/gatk/). The incidence of mutations was evaluated in a matching population using the 1000 Genome database.

\section{Plasmid and Animals}

A plasmid carrying human $\mathrm{Na}_{\mathrm{V}} 1.6$ $\left(\mathrm{hNa}_{\mathrm{V}} 1.6\right)$, purchased from Genionics, carries optimized codons for expression in mammalian cells. The channel was rendered resistant to tetrodotoxin (TTX-R) by a Tyr371Ser substitution so that it could be studied in voltage-clamp in isolation in ND7/23 cells (a rat DRG/mouse neuroblastoma hybrid cell line) and trigeminal ganglion (TRG) neurons from $\mathrm{Na}_{\mathrm{V}}$ 1.8-null mice (20). The Tyr371Ser and Met136Val substitutions were introduced into the channel using Quick Change XL site-directed mutagenesis kit (Stratagene). The identity of the insert was confirmed by Sanger sequencing at the Keck sequencing facility at Yale University.

Animal care followed a protocol approved by the Institutional Animal Care and Use Committee at the Veterans Administration Connecticut Healthcare System, West Haven. TRG from adult $\mathrm{Na}_{\mathrm{V}}$ 1.8-null mice were isolated and used for recording the resurgent current, while TRGs were isolated from male Sprague-Dawley albino rats (4-6 wks old, Harlan) and used for current-clamp studies.

Transient transfection of ND7/23 cells. $\mathrm{hNa}_{\mathrm{V}} 1.6 \mathrm{R}(\mathrm{WT})$ and $\mathrm{hNa}_{\mathrm{V}} 1.6-$ M136V (called Met136Val hereafter) were cotransfected with enhanced green fluorescent protein (EGFP) constructs into ND7/23 cells as previously described (21-23). Briefly, cells were plated at low density on $10 \mathrm{~mm}$ coverslips in 24-well plates and incubated at $37^{\circ} \mathrm{C}$ for $24 \mathrm{~h}$ before transfection. Cells were cotransfected with WT or Met136Val (0.5 ug/well) and EGFP (0.1 ug/well) (pEGFP, Clontech). Lipofectamine 2000 reagent $(1.5 \mu \mathrm{L})$ and DNA $(0.6 \mu \mathrm{g}$ total $)$ were each mixed with $50 \mu \mathrm{L}$ Opti-MEM (serum- and antibiotic-free) and incubated at room temperature $\left(\mathrm{RT}, 20^{\circ} \pm 1^{\circ} \mathrm{C}\right.$ ) for $5 \mathrm{~min}$. The two solutions were combined and incubated at RT for $20 \mathrm{~min}$. The combined mixture $(100 \mu \mathrm{L} /$ well $)$ was added to the ND7/23 cell culture medium (0.5 mL Dulbecco's modified Eagle medium [DMEM] plus 10\% fetal bovine serum [FBS] per well) and incubated at $37^{\circ} \mathrm{C}$ for $3 \mathrm{~h}$. Culture medium was replaced and cells were incubated at $37^{\circ} \mathrm{C}$ for $48 \mathrm{~h}$ before electrophysiological recordings.

Voltage-clamp in ND7/23 cells. ND7/23 cells with robust green fluorescence and WT or Met136Val were recorded on the same day under similar conditions (21-23). Whole-cell voltage-clamp recordings were performed using an EPC10-double amplifier and Patchmaster software (HEKA Electronik) at RT $\left(20^{\circ} \pm 1^{\circ} \mathrm{C}\right)$. The extracellular solution contained (in $\mathrm{mM}$ ): $140 \mathrm{NaCl}, 3 \mathrm{KCl}, 1 \mathrm{MgCl}_{2}, 1 \mathrm{CaCl}_{2}$, 10 N-2-hydroxyethylpiperazine-N'-2ethanesulfonic acid (HEPES), $5 \mathrm{CsCl}, 20$ TEA-Cl, $0.1 \mathrm{CdCl}_{2}$, pH 7.3 with $\mathrm{NaOH}$ (osmolarity adjusted to 320 mOsm with sucrose). Tetrodotoxin (TTX) (500 nM) was added to the bath to block endogenous TTX-sensitive sodium currents in ND7/23 cells (21-23). Patch pipettes were fabricated from borosilicate glass (1.65/1.1, OD/ID; World Precision Instruments) using a Sutter Instruments P-97 puller and had a resistance of 0.8-1.5 M $\Omega$. Transfected $\mathrm{ND} 7 / 23$ cells were held at $-120 \mathrm{mV}$ for all parameters examined. To minimize voltage errors, $70-90 \%$ series resistance compensation was applied. Currents were acquired $5 \mathrm{~min}$ after establishing whole-cell configuration. Recordings were acquired at $10 \mathrm{kHz}$ with low-pass Bessel filter and digitized at $50 \mathrm{kHz}$. Linear leak and residual capacitance artifacts were removed using $\mathrm{P} / 6$ subtraction.

To measure current-voltage (I-V) relationships, a range of potentials from $-80 \mathrm{mV}$ to $+40 \mathrm{mV}$ in $5 \mathrm{mV}$ increments were applied from the holding potential $(-120 \mathrm{mV})$ for $100 \mathrm{~ms}$ at $5 \mathrm{~s}$ intervals. 
Current density was calculated by normalizing maximal peak currents with cell capacitance. Peak inward currents obtained from activation protocols were converted to conductance values using the equation $\mathrm{G}=\mathrm{I} /\left(\mathrm{V}_{\mathrm{m}}-\mathrm{E}_{\mathrm{Na}}\right)$, where $\mathrm{G}$ is the conductance, $\mathrm{I}$ is the peak inward current, $\mathrm{V}_{\mathrm{m}}$ is the membrane potential used to elicit the response and $\mathrm{E}_{\mathrm{Na}}$ is the reversal potential for sodium. Conductance data were normalized by the maximum conductance value and fit with a Boltzmann equation, $\mathrm{G}=\mathrm{G}_{\min }+$ $\left(\mathrm{G}_{\max }-\mathrm{G}_{\min }\right) /\left(1+\exp \left[\mathrm{V}_{\mathrm{m}}-\mathrm{V}_{1 / 2}\right] / \mathrm{k}\right)$, where $\mathrm{V}_{1 / 2}$ is the midpoint of activation and $\mathrm{k}$ is the slope factor. Ramp currents were elicited with ramp depolarizations from -120 to $+20 \mathrm{mV}$ at a rate of $0.2 \mathrm{mV} / \mathrm{ms}$.

The ramp current was normalized to the maximal peak inward current recorded during the activation protocol for each cell.

Steady-state fast inactivation was assessed with a series of $100 \mathrm{~ms}$ prepulses $(-140 \mathrm{mV}$ to $0 \mathrm{mV}$ in $10 \mathrm{mV}$ increments) followed by a $40 \mathrm{~ms}$ step depolarization to $-10 \mathrm{mV}$ to activate the remaining noninactivated channels. Peak inward currents from steady-state fast inactivation were normalized by the maximum current amplitude and fit with a Boltzmann equation, $\mathrm{I}=\mathrm{I}_{\min }+1$ / $\left(1+\exp \left[\mathrm{V}_{\mathrm{m}}-\mathrm{V}_{1 / 2}\right] / \mathrm{k}\right)$, where I is the current amplitude measured during the test depolarization, $\mathrm{V}_{1 / 2}$ is the midpoint of fast-inactivation and $\mathrm{k}$ is the slope factor.

Steady-state slow inactivation was assessed with $30 \mathrm{~s}$ prepulses at a range of potentials from -120 to $+20 \mathrm{mV}$ in $10 \mathrm{mV}$ increments, followed by a 20 $\mathrm{ms}$ pulse to $-120 \mathrm{mV}$ to allow recovery from fast inactivation, and then a $20 \mathrm{~ms}$ depolarizing step to $-10 \mathrm{mV}$ to elicit a test response, which reflects the remaining channels available for activation. Peak inward currents from steady-state slow inactivation were normalized by the maximum current amplitude and fit with a Boltzmann equation, $\mathrm{I}=\mathrm{I}_{\min }+1$ / $\left(1+\exp \left[\mathrm{V}_{\mathrm{m}}-\mathrm{V}_{1 / 2}\right] / \mathrm{k}\right)$, where I is the current amplitude measured during the test depolarization, $\mathrm{V}_{1 / 2}$ is the midpoint of slow inactivation and $\mathrm{k}$ is the slope factor
Isolation and transfection of $\mathrm{Na}_{\mathrm{v}}$ 1.8null TRG neurons. TRG neurons from 4-to-8-wk-old $\mathrm{Na}_{\mathrm{V}}$ 1.8-null mice were harvested and dissociated as previously described (24). Briefly, dissected trigeminal ganglia were placed in ice-cold oxygenated complete saline solution (CSS) (in mM: $137 \mathrm{NaCl}, 5.3 \mathrm{KCl}, 1 \mathrm{MgCl} 2,25$ sorbitol, $3 \mathrm{CaCl}$, 10 HEPES; pH 7.2). After removal of roots and desheathing, ganglia were minced into small pieces and incubated with gentle agitation at $37^{\circ} \mathrm{C}$ for $20 \mathrm{~min}$ in oxygenated CSS containing $1.5 \mathrm{mg} / \mathrm{mL}$ Collagenase A (Roche Applied Science) and 0.6 mM ethylenediaminetetraacetic acid (EDTA), followed by a 17-min incubation with gentle agitation at $37^{\circ} \mathrm{C}$ in oxygenated CSS containing $1.5 \mathrm{mg} / \mathrm{mL}$ Collagenase $\mathrm{D}$ (Roche Applied Science), 0.6 mM EDTA and $30 \mathrm{U} / \mathrm{mL}$ papain (Worthington Biochemical). The solution was then aspirated and the ganglia carefully triturated in TRG media (DMEM/Fl2 [1:1, Invitrogen] with $100 \mathrm{U} / \mathrm{mL}$ penicillin, $0.1 \mathrm{mg} / \mathrm{mL}$ streptomycin [Invitrogen], $2 \mathrm{mM}$ L-glutamine [Invitrogen] and 10\% FBS [Hyclone]) containing $1.5 \mathrm{mg} / \mathrm{mL}$ bovine serum albumin (Sigma-Aldrich) and $1.5 \mathrm{mg} / \mathrm{mL}$ trypsin inhibitor (Sigma-Aldrich). After filtration through a 70- $\mu$ m nylon mesh (BD Biosciences), the cell suspension was centrifuged at $900 \times$ rpm for $3 \mathrm{~min}$ and cell pellet was ready for transfection. TRG neurons were cotransfected with EGFP and WT or Met136Val $\mathrm{Na}_{\mathrm{V}} 1.6_{\mathrm{R}}$ constructs using Nucleofector IIS (Lonza) and Basic Neuron SCN Nucleofector Kit (VSPI-1003; Amaxa). Recordings were conducted 40-48 h after transfection.

Resurgent current recordings in TRG neurons. Transfected small TRG neurons (20-25 $\mu \mathrm{m})$ with robust green fluorescence and no apparent neurites were selected for whole-cell patch-clamp recordings of the resurgent current within 40-48 $\mathrm{h}$ after transfection, using an EPC10-double amplifier and Patchmaster software (HEKA Electronik) at room temperature $\left(20^{\circ} \pm 1^{\circ} \mathrm{C}\right)$. The composition of the extracellular and pipette solutions and physical characteristics of the patch pipettes were the same as described for transfected ND7/23 cells above. TRG neurons were held at $-100 \mathrm{mV}$ and linear leak currents were subtracted using the $\mathrm{P} / 6$ method. To minimize voltage errors, we applied $80-90 \%$ series resistance compensation. Recordings were acquired $8 \mathrm{~min}$ after establishing wholecell configuration to allow steady-state dialysis between the cytoplasm and pipette solution. Recordings were acquired at $10 \mathrm{kHz}$ with low-pass Bessel filter and digitized at $50 \mathrm{kHz}$.

Resurgent currents were recorded with a two-step protocol where the membrane was depolarized to $+30 \mathrm{mV}$ for $20 \mathrm{~ms}$ from a holding potential of $-100 \mathrm{mV}$, followed by repolarization pulses to voltages from -10 to $-80 \mathrm{mV}$ in $5 \mathrm{mV}$ increments for $100 \mathrm{~ms}$, before returning to the holding potential. Only cells that showed slow rise and slow decay upon repolarization, typical of resurgent current (25), were included in our analysis. Resurgent current density was calculated by normalizing maximal peak resurgent current with cell capacitance.

Isolation and transfection of TRG neurons from adult rat. TRG from adult male Sprague-Dawley albino rats (4-6 wks old, Harlan) were isolated and cultured as described previously (24). WT and Met136Val Na $\mathrm{V}_{\mathrm{V}} 1.6_{\mathrm{R}}$ channels were transiently transfected into TRG neurons, along with EGFP, by electroporation with AmaxaTM Basic Neuron SCN Nucleofector Kit (Lonza) using program SCN-BNP6 on Nucleofector IIS (Lonza), as described previously (26). The ratio of sodium channel to GFP constructs was 10:1 (2 $\mu \mathrm{g}$ of WT or Met136Val plus $0.2 \mu \mathrm{g}$ of GFP). Transfected neurons were allowed to recover for $5 \mathrm{~min}$ at $37^{\circ} \mathrm{C}$ in $0.1 \mathrm{~mL}$ of calcium-free DMEM (Invitrogen), then diluted in TRG media containing $1.5 \mathrm{mg} / \mathrm{mL}$ bovine serum albumin and $1.5 \mathrm{mg} / \mathrm{mL}$ trypsin inhibitor. The cell suspension $(100 \mu \mathrm{l})$ was plated on each of $12 \mathrm{~mm}$ circular poly-D-lysine/laminin-coated coverslips (BD Biosciences) and incubated at $37^{\circ} \mathrm{C}$ in $5 \% \mathrm{CO}_{2}$ for $45 \mathrm{~min}$ for neurons to attach to the coverslips. TRG media (final volume of $1 \mathrm{~mL} /$ well), supplemented with $50 \mathrm{ng} / \mathrm{mL}$ (final concentration) each 
of mNGF (Alomone Labs) and GDNF (Peprotec), was then added and the cells maintained at $37^{\circ} \mathrm{C}$ in a humidified $5 \%$ $\mathrm{CO}_{2}$ incubator.

Current-clamp recordings in rat TRG neurons. Whole-cell current-clamp recordings were performed in transfected TRG neurons. The electrophysiologist was blinded to the sodium channel expressed in the TRG neurons until data were pooled into WT and Met136Val groups. Recordings were acquired at $10 \mathrm{kHz}$ with a low-pass Bessel filter and digitized at $50 \mathrm{kHz}$ using a HEKA EPC10-double amplifier. The extracellular solution contained (in $\mathrm{mM}$ ): $140 \mathrm{NaCl}, 3 \mathrm{KCl}, 2 \mathrm{MgCl}_{2}, 2 \mathrm{CaCl}_{2}$, 10 HEPES, 10 dextrose; $\mathrm{pH} 7.3$ with $\mathrm{NaOH}$ (osmolarity adjusted to $320 \mathrm{mOsm}$ $\mathrm{w}$ / sucrose). Patch pipettes (0.9-1.5 M 2 ) were fabricated from borosilicate glass (1.65/1.1, OD/ID; World Precision Instruments) using a Sutter Instruments P-97 puller and fire polished. Pipette solution contained (in $\mathrm{mM}$ ): $140 \mathrm{KCl}$, 0.5 EGTA, 5 HEPES, 3 Mg-ATP, 10 dextrose; pH 7.30 with $\mathrm{KOH}$ (adjusted to 310 mOsm with sucrose). TTX was not used in the bath for current-clamp recordings. Pipette potential was zeroed before seal formation, and the voltages were not corrected for liquid junction potential.

Whole-cell configuration was obtained in voltage-clamp mode before proceeding to current-clamp mode. Recordings were performed from small neurons (20-30 $\mu \mathrm{m})$ with ovoid cell bodies and neurite extensions that exhibited GFP fluorescence. All recordings were performed $40-50 \mathrm{~h}$ post-transfection at RT $\left(20^{\circ} \pm 1^{\circ} \mathrm{C}\right)$ and within an hour after coverslips were transferred to the recording chamber. TRG neurons with stable resting membrane potential ( $<10 \%$ variation) more negative than $-40 \mathrm{mV}$ and overshooting action potentials ( $>85 \mathrm{mV}$ peak to peak) were used for data analysis. Input resistance was determined by the slope of a linear fit to hyperpolarizing responses to current steps from $-5 \mathrm{pA}$ to $-40 \mathrm{pA}$ in $5 \mathrm{pA}$ increments. Current threshold was determined from the first action potential elicited by a series of depolarizing current injections (200 $\mathrm{ms}$ ) that increased in $5 \mathrm{pA}$ increments. Action potential frequency was determined by depolarizing current injections (500 ms). Voltage threshold was determined by assessing the first derivative of the membrane potential $(\mathrm{dV} / \mathrm{dt})$ and when the slope reached $20 \mathrm{mV} / \mathrm{ms}$.

\section{Data Analysis}

Data were analyzed offline with FitMaster (HEKA Electronik), Excel (Microsoft) and Origin 8.5 (Microcal Software) software and presented as mean \pm standard error (SE). Statistical significance was determined by unpaired Student $t$ test for voltage-clamp and current-clamp. Mann-Whitney test was used for comparison of firing frequencies between WT and Met136Val in response to stimuli ranging from 25 to $500 \mathrm{pA}$. Two-proportion z-test was used for comparison of spontaneous activity. Fisher's exact test was used for comparing high/low firing groups of cells expressing Met136Val and WT channels.

\section{RESULTS}

\section{Clinical Phenotype and Identification of Met136Val Mutation}

The subject was a 64-year-old Caucasian female of European heritage. She presented with classical TN in the second branch of the nerve for more than one year, with both spontaneous and evoked pain paroxysms, and no family history of similar symptoms. A diagnosis monitoring committee consisting of three experts on TN (27) confirmed the presence of NVC on the affected side by MRI and the diagnosis of TN. Whole-exome sequencing with good coverage (40X) of a set of genes encoding voltage-gated sodium channels $\left(\mathrm{Na}_{\mathrm{V}} 1.1,1.2,1.3,1.6\right.$ and 1.7) and calcium channels $\left(\mathrm{Ca}_{\mathrm{V}} 2.1\right.$ and 2.2) identified a single nucleotide substitution c.A406G (reference sequence NM_0141913) in the second coding exon of $S C N 8 A$, the gene that encodes $\mathrm{Na}_{\mathrm{V}} 1.6$. This mutation has not been previously reported and is absent from the $1000 \mathrm{Ge}$ nome database. This mutation substitutes methionine 136 by valine (Met136Val) in transmembrane segment 1 of domain 1 (DI/S1). This residue is highly conserved in all human $\mathrm{Na}_{\mathrm{V}} \mathrm{S}$ except for $\mathrm{Na}_{\mathrm{V}} 1.8$, where it is leucine (Figure 1). No other mutations in neuronal sodium channels $\mathrm{Na}_{\mathrm{V}} 1.1-1.3$ and $\mathrm{Na}_{\mathrm{V}} 1.7$ or $\mathrm{Ca}_{\mathrm{V}} 2.1$ and 2.2 were found in this individual.

\section{Voltage-Clamp Characterization of the Met136Val Channel}

The location of the mutation and its conservation among sodium channels suggested that it can have an effect at the channel level. Sodium currents were recorded in the voltage-clamp mode from ND7/ 23 cells transiently transfected with either $\mathrm{hNa} \mathrm{V}_{\mathrm{V}} 1.6_{\mathrm{R}} \mathrm{WT}$ or Met136Val mutant channels. Figures $2 \mathrm{~A}$ and B show representative traces of sodium current from WT and Met136Val mutant channels, respectively. The peak current density at $-5 \mathrm{mV}$ (Figure 2C) was significantly increased for Met136Val $(294 \pm 26.5 \mathrm{pA} / \mathrm{pF}, \mathrm{n}=14)$ by 1.5 -fold compared with WT channels $(189.4 \pm 11.3 \mathrm{pA} / \mathrm{pF}, \mathrm{n}=15, p=0.03)$. Met136Val did not alter the voltagedependence of activation $\left(\mathrm{V}_{1 / 2}: \mathrm{WT}\right.$, $-19.1 \pm 0.2 \mathrm{mV}, \mathrm{k}=6.5 \pm 0.2, \mathrm{n}=9$; Met136Val, $-16.8 \pm 0.1 \mathrm{mV}, \mathrm{k}=6.9 \pm 0.1$, $\mathrm{n}=10)$, fast inactivation $\left(\mathrm{V}_{1 / 2}: \mathrm{WT},-62.5\right.$ $\pm 0.5 \mathrm{mV}, \mathrm{k}=5.3 \pm 0.3, \mathrm{n}=12$; Met136Val, $-64.2 \pm 0.8 \mathrm{mV}, \mathrm{k}=5.3 \pm 0.4, \mathrm{n}=12)$ (Figure 2D), or slow inactivation $\left(\mathrm{V}_{1 / 2}: \mathrm{WT}\right.$, $-47.3 \pm 1.0, \mathrm{k}=10.1 \pm 0.7, \mathrm{n}=10$; Met136Val, $-48.0 \pm 1.5, \mathrm{k}=8.8 \pm 1.1, \mathrm{n}=9$ ) (Figure 2E).

We examined the response of WT and Met136Val channels to slow depolarizations using a ramp stimulus from a holding potential of $-120 \mathrm{mV}$ to $+20 \mathrm{mV}$ over $600 \mathrm{~ms}$ for a ramp rate of $0.2 \mathrm{mV} / \mathrm{ms}$. The ramp current was normalized to the maximal peak inward current recorded during the activation protocol for each cell. Peak ramp current of Met136Val measured $1.6 \pm 1.3 \%(n=6)$ of the peak current, and was not significantly different from WT $(3.0 \pm 2.2 \%, n=6)$. Persistent current, measured $70 \mathrm{~ms}$ after the onset of a step depolarization to $-10 \mathrm{mV}$ and normalized to the peak inward current, also showed no significant difference (WT: $1.6 \pm 0.2 \%$, $\mathrm{n}=15$; Met136Val: $1.5 \pm 0.3 \%, \mathrm{n}=14)$. 


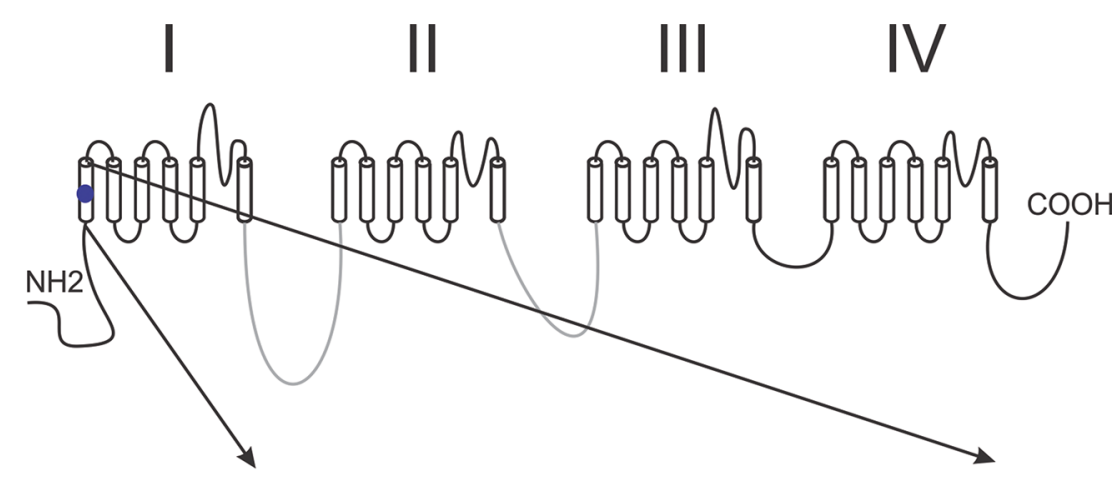

$\mathrm{Na}_{\mathrm{v}} 1.1$

$\mathrm{Na}_{\mathrm{v}} 1.2$

$\mathrm{Na}_{\mathrm{v}} 1 \cdot 3$

$\mathrm{Na}_{\mathrm{v}} 1.4$

$\mathrm{Na}_{\mathrm{v}} 1.5$

$\mathrm{Na}_{\mathrm{v}} 1.6$

$\mathrm{Na}_{\mathrm{v}} 1.7$

$\mathrm{Na}_{\mathrm{v}} 1.8$

$\mathrm{Na}_{\mathrm{v}} 1.9$

$\mathrm{Na}_{\mathrm{v}} 1 \cdot 6_{\mathrm{M} 136 \mathrm{v}}$

$\mathrm{Na}_{\mathrm{v}} 1 \cdot 7_{\text {I136V }}$
ILVHSLFSMLIMCTILTNCVF ILVHSLFNMLIMCTILTNCVF ILVHSLFSMLIMCTILTNCVF VLIHALF SMFIMITILTNCVF ILVHS L FNML IMCTILTNCVF ILIHSVFSMI IMCTILTNCVF ILVHSLFSMLIMCTILTNCIF VSVHSWESLFITVTILVNCVC VSVHSLFSMFI I GTVIINCVF ILIHSVFSVIIMCTILTNCVF ILVHSLFSMLIMCTVLTNCVF

Figure 1. Sequence alignment of domain I transmembrane segment 1. Alignment of the sequence of $\mathrm{DI} / \mathrm{S} 1$ from human $\mathrm{Na}_{\mathrm{V}}$ channels shows that Met136 is highly conserved in all human channels except $\mathrm{Na}_{\vee} 1.8$, where it is leucine.

\section{Resurgent Current of Met136Val Channel in TRG Neurons}

$\mathrm{Na}_{\mathrm{V}} 1.6$ channels produce resurgent currents that facilitate repetitive firing of neurons, including DRG neurons (25, 28-30). To examine whether enhanced peak current density of $\mathrm{Na}_{\mathrm{V}} 1.6$ channels is paralleled by increased resurgent current in the native neuronal background, we expressed WT and Met136Val channels in $\mathrm{Na}_{\mathrm{V}}$ 1.8-null TRG neurons. Representative traces of resurgent sodium currents are shown from WT (Figure 3A) and Met136Val mutant channels (Figure 3B). Resurgent currents were elicited by briefly depolarizing to $+30 \mathrm{mV}$ for $20 \mathrm{~ms}$ from a holding potential of $-100 \mathrm{mV}$, followed by a range of repolarization pulses from -10 to $-80 \mathrm{mV}$. Cells that showed slow rise and slow decay, typical of resurgent current and distinct from tail currents $(25,28)$, were used for analysis.

Resurgent current was observed in $71 \%$ of $\mathrm{Na}_{\mathrm{V}} 1.8$-null TRG neurons transfected with Met136Val (15 of 21 cells), whereas $50 \%$ of neurons transfected with the WT channels (12 of 24 cells) showed resurgent currents. The range in peak amplitude of the resurgent current was larger in neurons transfected with Met136Val (0.7 to $4.8 \mathrm{nA}, \mathrm{n}=15)$ compared with WT channels (0.3 to $2.0 \mathrm{nA}$, $\mathrm{n}=12)$. The average peak amplitude of the resurgent current was significantly larger (1.6X) in neurons transfected with Met136Val compared with WT channels (Met136Val: $1.8 \pm 0.3 \mathrm{nA}, \mathrm{n}=15$; WT: $1.1 \pm 0.1 \mathrm{nA}, \mathrm{n}=12 ; p<0.05$ ) (Figure 3C). Adjusting for cell capacitance, the peak resurgent current density was significantly increased in Met136Val mutant channels $(89.8 \pm 11.5 \mathrm{pA} / \mathrm{pF}, \mathrm{n}=15$; $p<0.05)$ compared with $\mathrm{Na}_{\mathrm{V}} 1.8$-null TRG neurons transfected with WT channels $(59.5 \pm 6.1 \mathrm{pA} / \mathrm{pF}, \mathrm{n}=12)$.

\section{Current-Clamp Analysis of TRG Neurons}

To assess the effects of Met136Val on the excitability of adult TRG neurons, which express a full complement of sodium channels, current-clamp recordings were performed on TRG neurons transfected with Met136Val or WT channels. Input resistance was not significantly different among neurons expressing Met136Val $(649 \pm 75 \mathrm{M} \Omega, \mathrm{n}=29)$ and WT channels $(601 \pm 93 \mathrm{M} \Omega, \mathrm{n}=29)$. The resting potential of TRG neurons expressing Met136Val channels $(-56.7 \pm$ $1.2 \mathrm{mV}, \mathrm{n}=29$ ) was not significantly different from that of TRG neurons expressing WT channels $(-57.1 \pm 0.8 \mathrm{mV}, \mathrm{n}=29)$.

To assess the effects of the variant channels on the current threshold of TRG neurons, we injected a series of depolarizing current pulses to evoke the first all-or-none action potential. TRG neurons that spontaneously fired were excluded from the analysis of evoked data. The current threshold of TRG neurons expressing Met136Val channels was significantly reduced compared with neurons expressing WT channels (Met136Val: $88.4 \pm 10.2 \mathrm{pA}, \mathrm{n}=29$; WT: $128.3 \pm 15.6 \mathrm{mV}, \mathrm{n}=29 ; p<0.05)$.

Voltage thresholds were determined by measuring the voltage at which the slope of the voltage trace $(\mathrm{dV} / \mathrm{dt})$ increases sharply at $20 \mathrm{mV} / \mathrm{ms}$. Voltage threshold in TRG neurons expressing Met136Val channels $(-20.3 \pm 1.5 \mathrm{mV}, \mathrm{n}=29)$ was similar to neurons expressing WT channels $(-19.2 \pm 1.5 \mathrm{mV}, \mathrm{n}=29)$. Action potential amplitude was measured as the difference 
A

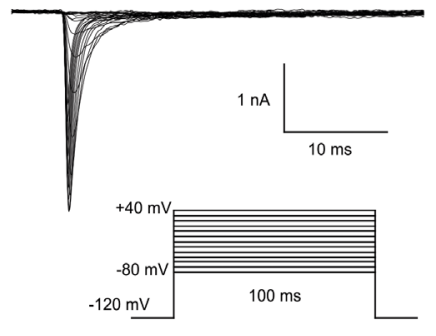

\section{C}

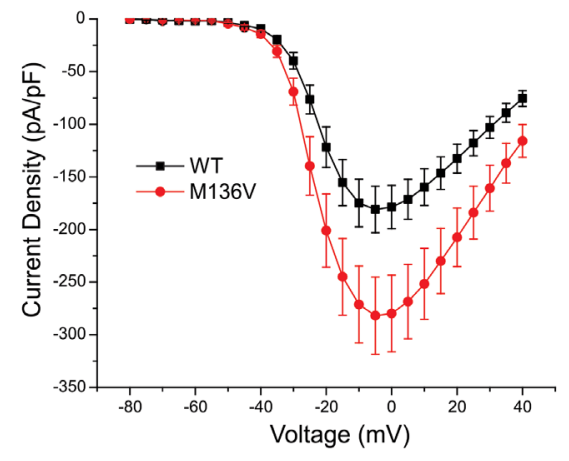

E

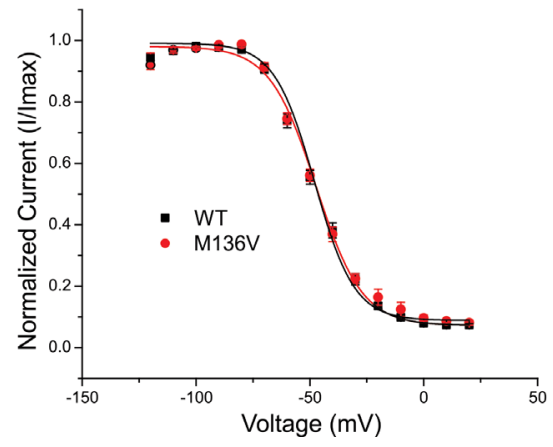

B

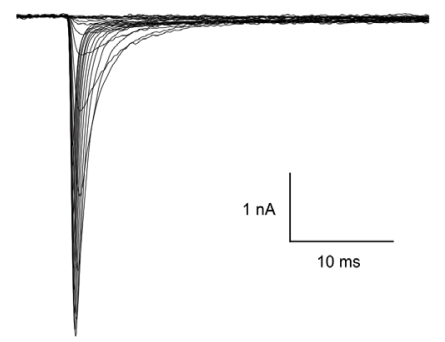

D

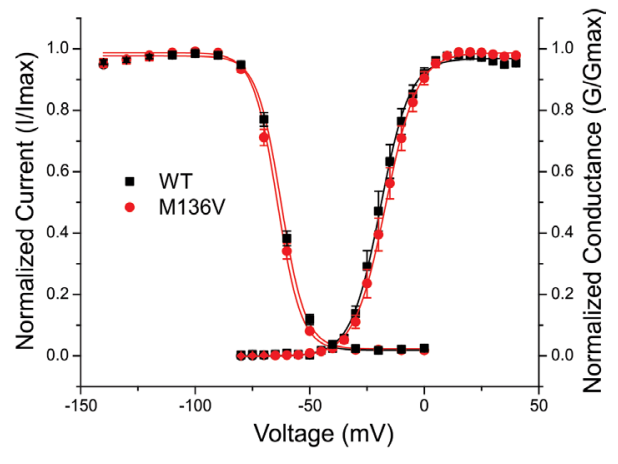

A

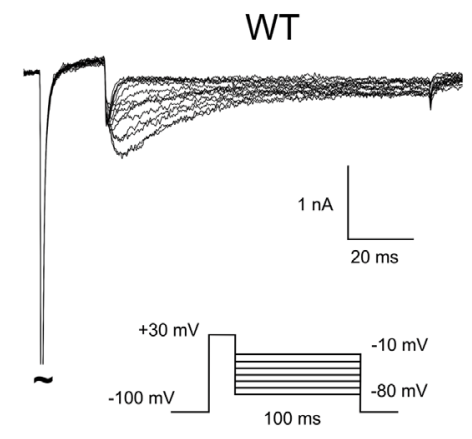

B

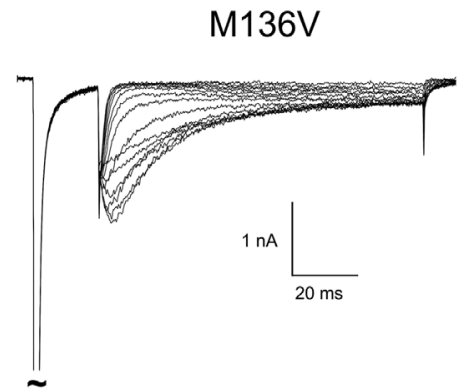

C

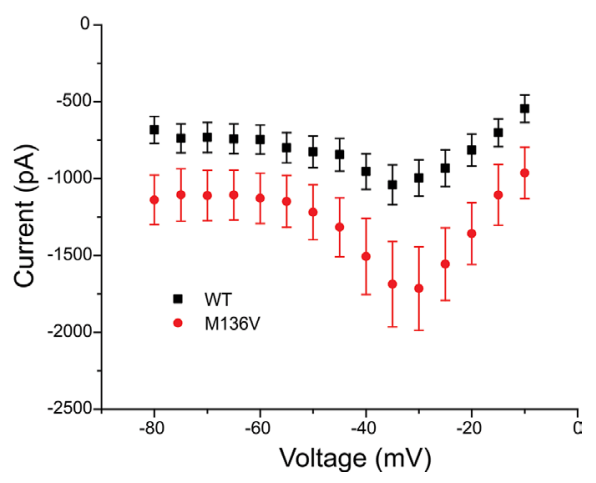

Figure 3. Resurgent sodium current increased in $\mathrm{Na}_{\mathrm{V}}$ 1.8-null TRG neurons expressing Met136Val channels. Representative traces of resurgent currents recorded from $\mathrm{Na}_{V}$ 1.8-null TRG neurons expressing either WT (A) or Met136Val (B) mutant channels. TRG neurons were held at $-100 \mathrm{mV}$ and depolarized to $+30 \mathrm{mV}$ for $20 \mathrm{~ms}$, followed by repolarization to a range of pulses $(-10 \mathrm{mV}$ to $-80 \mathrm{mV}$ ) to elicit resurgent current. (C) Average peak amplitudes of resurgent current recorded from WT $(n=12)$ and Met136Val $(n=15)$ show an average $60 \%$ increase in $\mathrm{Na}_{v} 1.8$ null TRG neurons expressing Met136Val mutant channels. Data represent mean \pm SE. different from that in neurons expressing WT channels (112.4 $\pm 2.2 \mathrm{mV}, \mathrm{n}=29)$. The half-width of action potentials evoked in TRG neurons expressing Met136Val channels $(2.8 \pm 0.2 \mathrm{~ms}, \mathrm{n}=29)$ was not peak of the action potential. The action potential amplitude of TRG neurons expressing Met136Val channels $(112.0 \pm$ $2.5 \mathrm{mV}, \mathrm{n}=29$ ) was not significantly 
significantly different from neurons expressing WT channels (WT: $3.0 \pm 0.3 \mathrm{~ms}$, $\mathrm{n}=29$ ).

The effect of the mutation on the excitability of TRG neurons was also assessed by analyzing the number of action potentials evoked by a series of depolarizing current injections (25-500 pA) for $500 \mathrm{~ms}$. TRG neurons expressing Met136Val channels fired a greater number of action potentials compared with WT channels in response to similar stimuli. Figure 4 shows representative responses of TRG neurons expressing WT or Met136Val channels evoked at one, two and three times the current threshold. Repetitive spike firing significantly increased in neurons expressing Met136Val between $100 \mathrm{pA}$ and 475 pA current injections compared with WT (Figure 4B, $p<0.05$ ). Interestingly, a scatter plot of the number of maximal action potentials fired during the series of depolarizing current injections shows low- and high-firing groups for TRG neurons that express WT or Met136Val channels. Low-firing neurons (8 cells in each group) are comparable between the two groups, firing 1-6 APs. The majority of the high-firing neurons (10 cells) expressing WT channels fired 8-21 APs and only 2 neurons fired $>15$ APs. In contrast, all high-firing neurons that expressed the Met136Val (14 cells) fired $\geq 15$ APs. Using a threshold of 15 APs, there were significantly more high-firing cells in TRG neurons expressing Met136Val channels $(14 / 22)$ compared with WT channels $(2 / 18, p=0.001$; Table 1$)$.

Neurons that are transfected with $\mathrm{Na}_{\mathrm{V}} 1.6$ channels demonstrate a propensity for spontaneous firing. Spontaneous action potentials recorded for $30 \mathrm{~s}$ in a representative TRG neuron expressing Met136Val channels is shown in Figure $5 \mathrm{~A}$, as well as an expansion of the time scale of the same trace illustrating a single action potential (Figure 5B). Spontaneous firing was observed in $41 \%$ and $48 \%$ of TRG neurons transfected with Met136Val and WT channels, respectively (Met136Val, 20/49 cells; WT, $27 / 56$ cells, $p=0.40$; Figure 5C). TRG

A
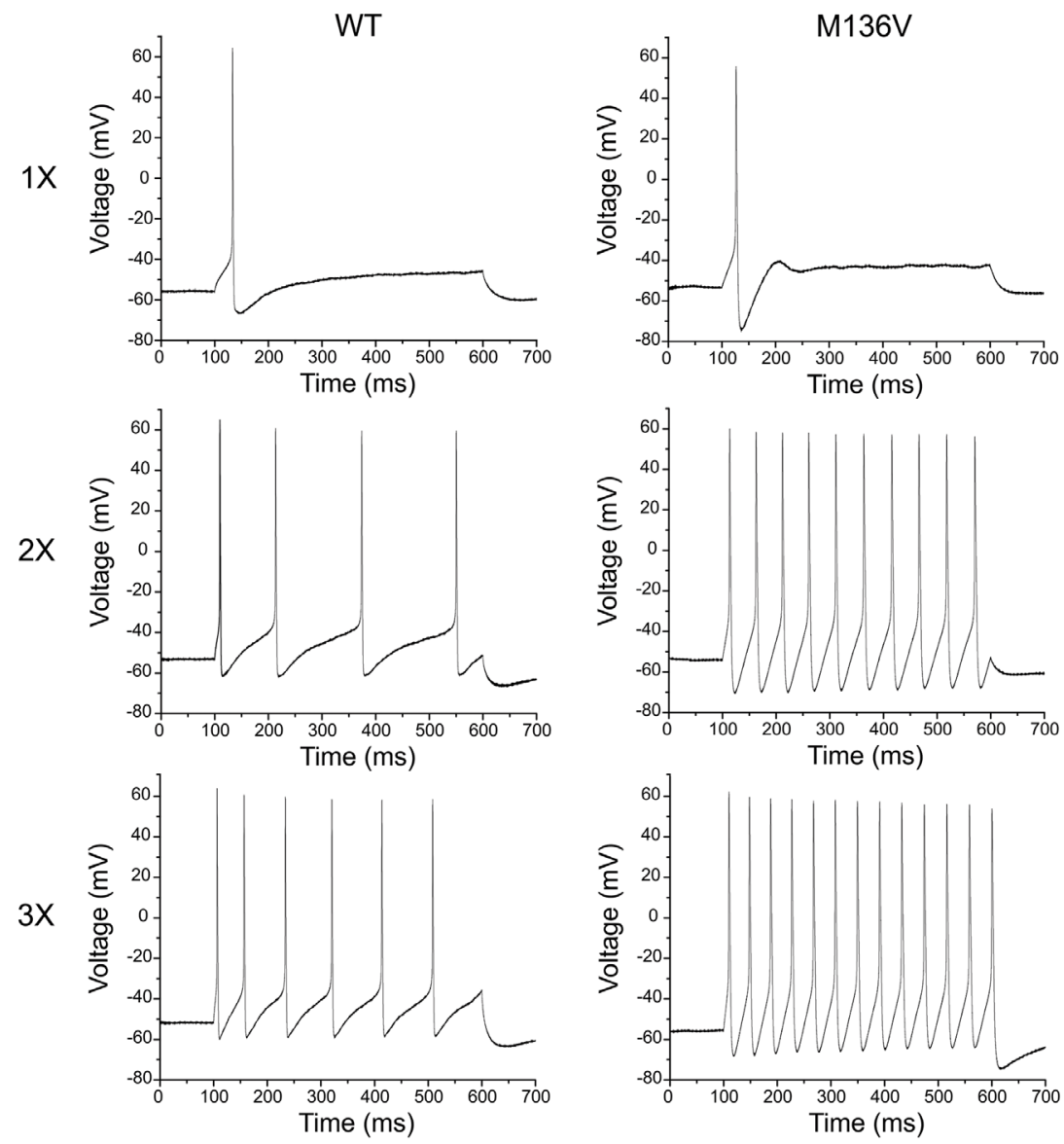

B

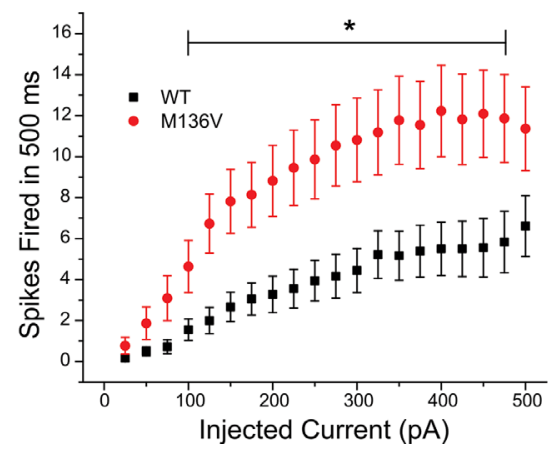

C

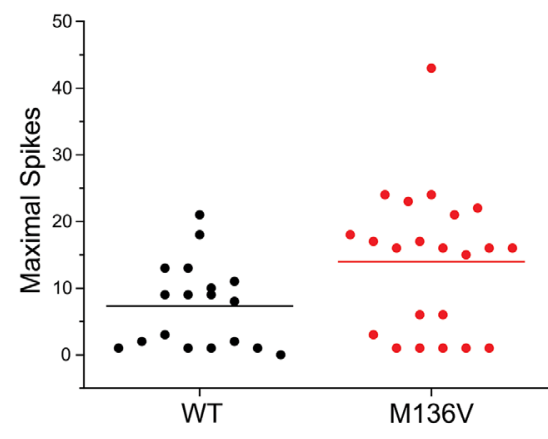

Figure 4. Met136Val channels increase excitability in TRG neurons. (A) Representative responses of TRG neurons expressing WT or Met136Val channels to $500 \mathrm{~ms}$ sustained depolarizations in current steps one, two and three times (top, middle, bottom traces, respectively) the current threshold for action potential generation. (B) Comparison of repetitive action potential firing between TRG neurons expressing WT (black; $n=18$ ) and Met136Val (red; $n=22$ ) across a series of 500 ms current injections from 25-500 pA; $p<0.05$.

neurons expressing Met136Val or WT channels fired spontaneously at comparable frequencies of $4.2 \pm 0.9 \mathrm{~Hz}$ and $4.2 \pm 0.8 \mathrm{~Hz}$, respectively. A single action potential from each spontaneously firing cell was used to determine the voltage threshold. Although the voltage threshold of spontaneously firing cells was 
Table 1. Proportion of low- and high-firing TRG neurons expressing Met136Val or WT channels.

\begin{tabular}{lcc}
\hline & $\mathrm{hNa}_{\mathrm{v}} 1.6 \mathrm{R}$ & $\mathrm{hNa}_{\mathrm{v}} 1.6 \mathrm{R}-\mathrm{M} 136 \mathrm{~V}$ \\
\hline Low-firing & 16 & 8 \\
High-firing & 2 & $14^{*}$ \\
& \multicolumn{2}{c}{ P value 0.001} \\
\hline
\end{tabular}

determined to be similar between TRG neurons expressing Met136Val or WT channels (Met136Val: $-28.3 \pm 1.2 \mathrm{mV}$, $\mathrm{n}=20$; WT: $-28.7 \pm 0.9 \mathrm{mV}, \mathrm{n}=27$ ), this was much lower than the voltage threshold measured for evoked action potentials by approximately $-10 \mathrm{mV}$.

\section{DISCUSSION}

Genetic and functional evidence support a role for the SCN8A c.406A > G (p.Met136Val) mutation in TN. The mutation substitutes a highly conserved residue in DI/S1 of the channel, and has not been reported in the 1000 Genome database. The Met136Val substitution produces a significant increase in peak transient and resurgent currents of $\mathrm{Na}_{\mathrm{V}} 1.6$, reduces the threshold for action potential in TRG neurons, and enhances the neuronal evoked response and the fraction of neurons that fire at a higher rate than those expressing WT channels. Compared to other DI-S1 sodium channel mutations that have been linked to familial febrile seizures (31), erythromelalgia (32) and myotonia (33), the Met136Val mutation does not alter gating properties, which points to isoform-specific effects of mutations in this transmembrane segment. The increased peak transient and resurgent currents that confer hyperexcitability at the neuronal level combined with the rare occurrence of this mutation increase our confidence in concluding that Met136Val is a clinically significant variant that contributes to the pathophysiology of TN.

The paroxysmal nature of TN, the occurrence of intense afterdischarges and favorable response to carbamazepine are consistent with a role for voltage-gated sodium channels. $\mathrm{Na}_{\mathrm{V}} 1.6$ channels are predominant at axon initial segments (AISs) and mature nodes of Ranvier in myelinated fibers of the central and peripheral nervous system (34-37). $\mathrm{Na}_{\mathrm{V}} 1.6$ is also expressed in small DRG neurons that produce unmyelinated C-fibers, and total loss of this channel in DRG neurons slows C-fiber conduction in the sciatic nerve (38), suggesting that it contributes to the transmission of noxious signals in these fibers. We have previously shown that $\mathrm{Na}_{\mathrm{V}} 1.6$ is widely expressed in TRG neurons, giving rise to myelinated and unmyelinated fibers, and is localized in the nerve endings of unmyelinated fibers in the cornea (38), which are thought to be almost entirely nociceptive (39). Animal studies support a role for $\mathrm{Na}_{\mathrm{V}} 1.6$ in nerve injury models (40), toxin-induced pain (41), chemotherapy-induced pain (42) and local DRG inflammatory pain $(43,44)$. Thus, $\mathrm{Na}_{\mathrm{V}} 1.6$ is poised to play an important role in the pathophysiology of chronic pain, including in TN.

$\mathrm{Na}_{\mathrm{V}} 1.6$ channels manifest distinctive gating properties consistent with a critical role in regulating firing in the different neurons in which they are expressed. $\mathrm{Na}_{\mathrm{V}} 1.6$ produces a rapidly repriming fast-inactivating TTX-S current (45-47) and a persistent current $(47,48)$, which allow this channel to contribute to the overshoot of action potential in sensory neurons (49). Voltage-clamp recordings show that the Met136Val mutation significantly increases the peak current density. The increase in current density may have contributed to the reduction in current threshold for firing action potentials $(\sim 30 \%)$.

$\mathrm{Na}_{\mathrm{V}} 1.6$ produces a resurgent current in both CNS neurons and DRG neurons $(28,29)$ as a result of channel reopening upon repolarization of the membrane (25). The resurgent current shortens refractory periods, thus supporting repetitive and burst firing of neurons (50), and has been implicated in human pain conditions caused by mutations in $\mathrm{Na}_{\mathrm{v}} 1.7(30,51,52)$ and in an animal model of radicular pain induced by local DRG inflammation (53). Our data show that Met136Val channels produce, on average, a 1.6-fold increase in the resurgent current in TRG neurons;

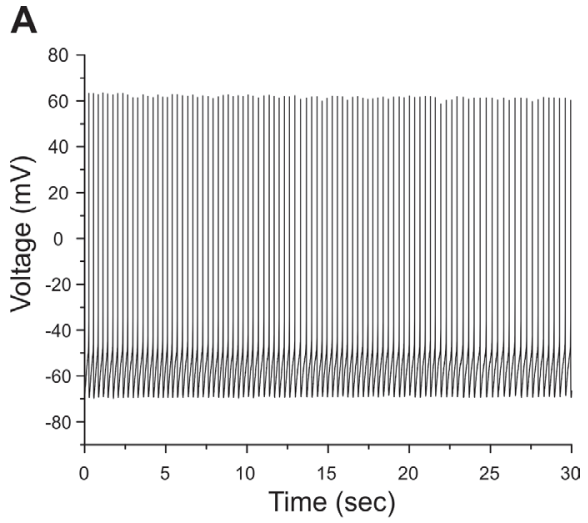

B
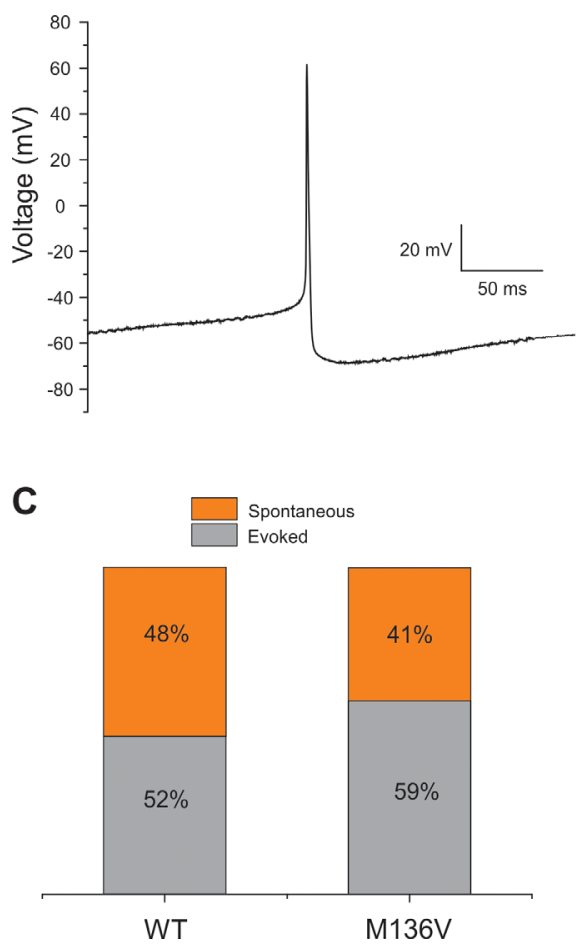

Figure 5. Spontaneous firing of TRG neurons transfected with Met136Val mutant channels. (A) Representative current-clamp traces of spontaneous firing in TRG neurons expressing Met136Val mutant channels. The traces were recorded for $30 \mathrm{~s}$ without current injection. (B) Expansion of a single action potential from a spontaneously firing cell expressing M136V channels shown in (A). (C) Bar graphs showing the proportion of spontaneous firing cells (orange) compared with evoked cells (gray) for TRG neurons expressing WT and Met136Val mutant channels. Numbers in the bar show the percentage values for WT and Met136Val mutant channels. 
the range of resurgent current amplitude in cells expressing WT channels is 0.3$2.4 \mathrm{nA}$, whereas resurgent currents in neurons that express the Met136Val channels range from $0.7-4.8 \mathrm{nA}$. We previously showed that roughly half of the small DRG neurons that are transfected with WT $\mathrm{Na}_{\mathrm{V}} 1.6$ channels produce resurgent currents (29). This is consistent with data showing that production of resurgent currents is cell-type-dependent (50), suggesting a cell-type-specific expression of an open channel blocker necessary for generating the resurgent current. The low-firing group of TRG neurons detected by the repetitive firing protocol possibly do not express an endogenous open channel blocker and do not produce a resurgent current, but such a blocker is likely present in the high-firing group of TRG neurons that produce a resurgent current. The increase in resurgent current of Met136Val channels provides the physiological basis for the enhanced evoked firing of TRG neurons that express these channels.

One possible mechanism that could link the mutation described here to TN involves ephaptic transmission, or electrotonic cross-talk between nearby axons, which has been proposed $(54,55)$ as a mechanism contributing to hemifacial spasm. There have been multiple demonstrations of ephaptic interactions that can lead to ectopic impulse activity, not only between closely apposed uninjured axons (56) but also between injured axons $(57,58)$ and between neighboring dysmyelinated axons (59). It has been suggested that demyelination due to compression is present in some cases of trigeminal neuralgia $(2,60,61)$. It is well established that myelinated axons can produce large external electrical fields in regions where myelin is focally absent (62). Moreover, it has been demonstrated that increases in sodium channel density increase the likelihood of action potential generation in demyelinated axons (63).

The significant hyperexcitability of TRG neurons in which the Met136Val mutant channels are expressed is in agreement with the predictions of the ignition theory of TN. According to ignition theory, $\mathrm{TN}$ is triggered by ectopic afterdischarges that are either spontaneous or low-threshold evoked phenomena leading to paroxysmal pain $(11,12)$. An increase in peak transient and resurgent current could be linked to the evoked repetitive firing, which would be consistent with the evoked pain phenomenon in $\mathrm{TN}$. The high prevalence of spontaneous firing of TRG neurons overexpressing WT channels may have masked the real effect of mutant channels in rendering TRG neurons spontaneously firing when both WT and mutant channels were present at physiological levels. Additionally, we cannot formally discount the possible role of inflammatory mediator sensitization of primary afferents in TN due to NVC, which could lead to spontaneous excitability of TRG neurons.

\section{CONCLUSION}

The genetic and functional data presented in this study support a link of a gain-of-function mutation in $\mathrm{Na}_{\mathrm{V}} 1.6$ to human pain disorders, expanding the clinical-genetic spectrum of excitability disorders caused by this channel. Early-onset seizures and intellectual disabilities associated with human $\mathrm{Na}_{\mathrm{V}} 1.6$ mutations in infantile epileptic encephalopathy (64) may mask any pain phenotype in these individuals. Whole-exome screening of a number of relevant ion channel genes and functional testing in relevant cell background increase confidence in the utility of this approach for discovering pathogenic mutations in pain disorders of unknown etiology.

\section{ACKNOWLEDGMENTS}

We thank the subject for participating in this study. We thank Lawrence Macala and Palak Shah for technical support. This work was supported by the Medical Research Service and Rehabilitation Research Service, Department of Veterans Affairs (SGW and SDH), and by funding to Yale University from Convergence Pharmaceuticals. The Center for Neuroscience and Regeneration Research is a collaboration of the Paralyzed Veterans of America with Yale University.

\section{DISCLOSURE}

VM and ST are employees of Convergence Pharmaceuticals, a Biogen company.

\section{REFERENCES}

1. Cruccu G, Bonamico LH, Zakrzewska JM. (2010) Cranial neuralgias. Handb. Clin. Neurol. 97:663-78.

2. Devor M, Govrin-Lippmann R, Rappaport ZH. (2002) Mechanism of trigeminal neuralgia: an ultrastructural analysis of trigeminal root specimens obtained during microvascular decompression surgery. J. Neurosurg. 96:532-43.

3. Maarbjerg S, Wolfram F, Gozalov A, Olesen J, Bendtsen L. (2015) Significance of neurovascular contact in classical trigeminal neuralgia. Brain. 138:311-19.

4. Antonini G, et al. (2014) Magnetic resonance imaging contribution for diagnosing symptomatic neurovascular contact in classical trigeminal neuralgia: a blinded case-control study and meta-analysis. Pain. 155:1464-71.

5. Lee A, McCartney S, Burbidge C, Raslan AM, Burchiel KJ. (2014) Trigeminal neuralgia occurs and recurs in the absence of neurovascular compression. J. Neurosurg. 120:1048-54.

6. Ko AL, et al. (2015) Trigeminal neuralgia without neurovascular compression presents earlier than trigeminal neuralgia with neurovascular compression. J. Neurosurg. 123:1519-27.

7. Bozkurt M, et al. (2012) Management of bilateral trigeminal neuralgia with trigeminal radiofrequency rhizotomy: a treatment strategy for the life-long disease. Acta. Neurochir. (Wien.) 154: 785-91; discussion 791-2.

8. Wang Y, Yu CY, Huang L, Riederer F, Ettlin D (2011) Familial neuralgia of occipital and intermedius nerves in a Chinese family. J. Headache Pain. 12:497-500.

9. Riederer F, Sandor PS, Linnebank M, Ettlin DA. (2010) Familial occipital and nervus intermedius neuralgia in a Swiss family. J Headache Pain 11:335-8.

10. El Otmani H, Moutaouakil F, Fadel H, Slassi I. (2008) [Familial trigeminal neuralgia]. Rev. Neurol. (Paris) 164:384-7.

11. Rappaport ZH, Devor M. (1994) Trigeminal neuralgia: the role of self-sustaining discharge in the trigeminal ganglion. Pain. 56:127-38.

12. Devor M, Amir R, Rappaport ZH. (2002) Pathophysiology of trigeminal neuralgia: the ignition hypothesis. Clin. J. Pain. 18:4-13.

13. Burchiel KJ, Baumann TK. (2004) Pathophysiology of trigeminal neuralgia: new evidence from a trigeminal ganglion intraoperative microneurographic recording. Case report. J. Neurosurg. 101:872-3.

14. Dib-Hajj SD, Yang Y, Black JA, Waxman SG. (2013) The $\mathrm{Na}_{\mathrm{V}} 1.7$ sodium channel: from molecule to man. Nat. Rev. Neurosci. 14:49-62. 
15. Dib-Hajj SD, Waxman SG. (2014) Translational pain research: Lessons from genetics and genomics. Sci. Transl. Med. 6:249sr244.

16. Dib-Hajj SD, Black JA, Waxman SG. (2015) NaV1.9: a sodium channel linked to human pain. Nat. Rev. Neurosci. 16:511-19.

17. Blanchard MG, et al. (2015) De novo gain-offunction and loss-of-function mutations of SCN8A in patients with intellectual disabilities and epilepsy. J. Med. Genet. 52:330-7

18. Estacion M, et al. (2014) A novel de novo mutation of SCN8A (Nav1.6) with enhanced channel activation in a child with epileptic encephalopathy. Neurobiol. Dis. 69:117-23.

19. Veeramah KR, et al. (2012) De Novo Pathogenic SCN8A Mutation Identified by Whole-Genome Sequencing of a Family Quartet Affected by Infantile Epileptic Encephalopathy and SUDEP. Am. J. Hum. Genet. 90:502-10.

20. Stirling LC, et al. (2005) Nociceptor-specific gene deletion using heterozygous $\mathrm{Na}_{\mathrm{v}} 1.8$-Cre recombinase mice. Pain. 113:27-36.

21. Wittmack EK, et al. (2004) Fibroblast growth factor homologous factor 2B: association with Nav1.6 and selective colocalization at nodes of Ranvier of dorsal root axons. J. Neurosci. 24:6765-75.

22. Wittmack EK, Rush AM, Hudmon A, Waxman SG, Dib-Hajj SD. (2005) Voltage-gated sodium channel Nav1.6 is modulated by p38 mitogen-activated protein kinase. J. Neurosci. 25:6621-30.

23. Gasser A, et al. (2010) Two Nedd4-binding motifs underlie modulation of sodium channel Nav1.6 by p38 MAPK. J. Biol. Chem. 285:26149-61.

24. Estacion M, et al. (2011) Intra- and interfamily phenotypic diversity in pain syndromes associated with a gain-of-function variant of NaV1.7. Mol. Pain. 7:92.

25. Raman IM, Bean BP. (1997) Resurgent sodium current and action potential formation in dissociated cerebellar Purkinje neurons. J. Neurosci. 17:4517-26.

26. Dib-Hajj SD, et al. (2009) Transfection of rat or mouse neurons by biolistics or electroporation. Nat. Protoc. 4:1118-26.

27. Zakrzewska JM, et al. (2013) Novel design for a phase IIa placebo-controlled, double-blind randomized withdrawal study to evaluate the safety and efficacy of CNV1014802 in patients with trigeminal neuralgia. Trials. 14:402.

28. Raman IM, Sprunger LK, Meisler MH, Bean BP. (1997) Altered subthreshold sodium currents and disrupted firing patterns in Purkinje neurons of Scn8a mutant mice. Neuron. 19:881-91.

29. Cummins TR, Dib-Hajj SD, Herzog RI, Waxman SG. (2005) Nav1.6 channels generate resurgent sodium currents in spinal sensory neurons. FEBS Letters. 579:2166-70.

30. Jarecki BW, Piekarz AD, Jackson JO 2nd, Cummins TR. (2010) Human voltage-gated sodium channel mutations that cause inherited neuronal and muscle channelopathies increase resurgent sodium currents. J. Clin. Invest. 120:369-78.
31. Mantegazza M, et al. (2005) Identification of an Nav1.1 sodium channel (SCN1A) loss-of-function mutation associated with familial simple febrile seizures. Proc. Natl. Acad. Sci. U.S.A. 102: 18177-182.

32. Cheng X, Dib-Hajj SD, Tyrrell L, Waxman SG. (2008) Mutation I136V alters electrophysiological properties of the NaV1.7 channel in a family with onset of erythromelalgia in the second decade. Mol. Pain. 4:1.

33. Petitprez S, et al. (2008) A novel dominant mutation of the Nav1.4 alpha-subunit domain I leading to sodium channel myotonia. Neurology. 71:1669-75.

34. Caldwell JH, Schaller KL, Lasher RS, Peles E, Levinson SR. (2000) Sodium channel $\mathrm{Na}_{\mathrm{v}} 1.6$ is localized at nodes of ranvier, dendrites, and synapses. Proc. Natl. Acad. Sci. U.S.A. 97:5616-20.

35. Schafer DP, Custer AW, Shrager P, Rasband MN (2006) Early events in node of Ranvier formation during myelination and remyelination in the PNS. Neuron Glia Biol. 2:69-79.

36. Black JA, et al. (1996) Spinal sensory neurons express multiple sodium channel alpha-subunit mRNAs. Mol. Brain Res. 43:117-31.

37. Dib-Hajj SD, Cummins TR, Black JA, Waxman SG. (2010) Sodium channels in normal and pathological pain. Аnnu. Rev. Neurosci. 33:325-47.

38. Black JA, Renganathan M, Waxman SG. (2002) Sodium channel $\mathrm{Na}_{\mathrm{v}} 1.6$ is expressed along nonmyelinated axons and it contributes to conduction. Mol. Brain Res. 105:19-28.

39. Chen X, Gallar J, Pozo MA, Baeza M, Belmonte C. (1995) CO2 stimulation of the cornea: a comparison between human sensation and nerve activity in polymodal nociceptive afferents of the cat. Eur. J. Neurosci. 7:1154-63.

40. Henry MA, Freking AR, Johnson LR, Levinson SR. (2007) Sodium channel Nav1.6 accumulates at the site of infraorbital nerve injury. $B M C$ Neurosci. 8:56.

41. Deuis JR, et al. (2013) An animal model of oxaliplatin-induced cold allodynia reveals a crucial role for Na1.6 in peripheral pain pathways. Pain. 154:1749-57.

42. Sittl R, et al. (2012) Anticancer drug oxaliplatin induces acute cooling-aggravated neuropathy via sodium channel subtype $\mathrm{Na}_{\mathrm{v}} 1$.6-resurgent and persistent current. Proc. Natl. Acad. Sci. U.S.A. 109:6704-9.

43. Xie W, Strong JA, Ye L, Mao JX, Zhang JM. (2013) Knockdown of sodium channel Na1.6 blocks mechanical pain and abnormal bursting activity of afferent neurons in inflamed sensory ganglia. Pain. 154:1170-80.

44. Xie W, Strong JA, Zhang JM. (2015) Local knockdown of the Na1.6 sodium channel reduces pain behaviors, sensory neuron excitability, and sympathetic sprouting in rat models of neuropathic pain. Neuroscience. 291:317-30.

45. Herzog RI, Cummins TR, Ghassemi F, Dib-Hajj SD, Waxman SG. (2003) Distinct repriming and closed-state inactivation kinetics of Nav1.6 and Nav1.7 sodium channels in mouse spinal sensory neurons. J .Physiol. (Lond.) 551:741-50.

46. Sangameswaran L, et al. (1997) A novel tetrodotoxin-sensitive, voltage-gated sodium channel expressed in rat and human dorsal root ganglia. J. Biol. Chem. 272:14805-9.

47. Smith MR, Smith RD, Plummer NW, Meisler MH, Goldin AL. (1998) Functional analysis of the mouse Scn8a sodium channel. J. Neurosci. 18:6093-102.

48. Rush AM, Dib-Hajj SD, Waxman SG. (2005) Electrophysiological properties of two axonal sodium channels, Nav1.2 and Nav1.6, expressed in mouse spinal sensory neurons. J. Physiol. (Lond.) 564:803-15.

49. Rush AM, Cummins TR, Waxman SG. (2007) Multiple sodium channels and their roles in electrogenesis within dorsal root ganglion neurons. J. Physiol. (Lond.) 579(Pt 1):1-14.

50. Lewis AH, Raman IM. (2014) Resurgent current of voltage-gated $\mathrm{Na}(+)$ channels. J. Physiol. 592:4825-38.

51. Faber CG, et al. (2012a) Gain of function $\mathrm{Na}_{\mathrm{v}} 1.7$ mutations in idiopathic small fiber neuropathy. Ann. Neurol. 71:26-39.

52. Han C, et al. (2012b) Functional profiles of SCN9A variants in dorsal root ganglion neurons and superior cervical ganglion neurons correlate with autonomic symptoms in small fibre neuropathy. Brain. 135:2613-28.

53. Xie W, et al. (2016) Upregulation of the sodium channel NaVbeta4 subunit and its contributions to mechanical hypersensitivity and neuronal hyperexcitability in a rat model of radicular pain induced by local DRG inflammation. Pain. 157:879-91.

54. Nielsen VK. (1984) Pathophysiology of hemifacial spasm: I. Ephaptic transmission and ectopic excitation. Neurology. 34:418-26.

55. Sanders DB. (1989) Ephaptic transmission in hemifacial spasm: a single-fiber EMG study. Muscle Nerve. 12:690-4

56. Ramon F, Moore JW. (1978) Ephaptic transmission in squid giant axons. Am. J. Physiol. 234: C162-69.

57. Seltzer Z, Devor M. (1979) Ephaptic transmission in chronically damaged peripheral nerves. Neurology. 29:1061-4.

58. Lisney SJ, Pover CM. (1983) Coupling between fibres involved in sensory nerve neuromata in cats. J. Neurol. Sci. 59:255-64.

59. Rasminsky M. (1980) Ephaptic transmission between single nerve fibres in the spinal nerve roots of dystrophic mice. J. Physiol. 305:151-69.

60. Love S, Hilton DA, Coakham HB. (1998) Central demyelination of the $\mathrm{Vth}$ nerve root in trigeminal neuralgia associated with vascular compression. Brain Pathol. 8:1-11; discussion 11-12.

61. Lagares A, Rivas JJ, Jimenez L, Cicuendez M, Avendano C. (2010) Central demyelination in the pathogenesis of trigeminal neuralgia associated with cerebellopontine angle tumors: case report with ultrastructural trigeminal root analysis. Neurosurgery. 66: E841-42. 
NAVI.6 MUTATION LINKED TO TRIGEMINAL PAIN

62. Waxman SG, Pappas GD, Bennett MV. (1972) Morphological correlates of functional differentiation of nodes of Ranvier along single fibers in the neurogenic electric organ of the knife fish Stern archus. J. Cell Biol. 53:210-24.

63. Waxman SG, Wood SL. (1984) Impulse conduction in inhomogeneous axons: effects of variation in voltage-sensitive ionic conductances on invasion of demyelinated axon segments and preterminal fibers. Brain Res. 294:111-22.

64. Wagnon JL, Meisler MH. (2015) Recurrent and Non-Recurrent Mutations of SCN8A in Epileptic Encephalopathy. Front Neurol. 6:104.

Cite this article as: Tanaka BS, et al. (2016) A gain-of-function mutation in Nav1.6 in a case of trigeminal neuralgia. Mol. Med. 22:338-48. 